\title{
Hydrocarbon ions in the lower ionosphere of Saturn
}

\author{
Y. H. Kim, ${ }^{1,2}$ Jane L. Fox, ${ }^{1}$ J. H. Black, ${ }^{3}$ and J. I. Moses ${ }^{4}$ \\ Received 9 May 2013; revised 5 November 2013; accepted 9 November 2013; published 7 January 2014.
}

[1] Radio occultation measurements of the Saturn ionosphere have shown that persistent but variable electron density layers appear well below the major peaks. We model here the region of hydrocarbon ions that is below the main peak and is produced by absorption of solar photons in the wavelength range 842 to $1116 \AA$, which penetrate to altitudes below the methane homopause in the wings of the $\mathrm{H}_{2}$ absorption lines, and in the gaps between groups of lines. In this wavelength range, $\mathrm{H}_{2}$ absorbs photons in discrete transitions to rovibrational levels of electronically excited states, which then decay to a range of rovibrational levels of the electronic ground state, or to the continuum of the ground state. The cross sections for these discrete absorptions vary by several orders of magnitude from the peaks to the wings of the absorption lines. We find that the adoption of high resolution photoabsorption cross sections for the $\mathrm{H}_{2}$ bands leads to different photoionization profiles for both the hydrocarbons and $\mathrm{H}$ atoms, and to peak $\mathrm{CH}_{4}^{+}$ photoproduction profiles that are more than an order of magnitude larger than those computed with low resolution cross sections. For the present model, we find that ionization by energetic electrons that accompany the absorption of soft X-rays appears in the same altitude range. We predict that a broad region of hydrocarbon ions appears well below the main peak, in the altitude range 600 to $1000 \mathrm{~km}$ above the 1 bar level (2-0.04 $\mu$ bar) with a maximum electron density of $\sim 3 \times 10^{3} \mathrm{~cm}^{-3}$ at low solar activity.

Citation: Kim, Y. H., J. L. Fox, J. H. Black, and J. I. Moses (2014), Hydrocarbon ions in the lower ionosphere of Saturn, J. Geophys. Res. Space Physics, 119, 384-395, doi:10.1002/2013JA019022.

\section{Introduction}

[2] Radio occultation (RO) and in situ experiments have shown that persistent but variable electron density layers are observed near and below the main peaks for solar system bodies that have well-developed ionospheres, including that of Saturn [e.g., Atreya, 1986; Nagy et al., 2006; Kliore et al., 2009]. The suggested sources for these lower layers include absorption of solar X-rays in the $\sim 1-150 \AA$ range, precipitation of very energetic charged particles, ablation of meteoric particles, and, for Earth, ionization of NO by solar Lyman alpha radiation. Lyman alpha photons penetrate to very low altitudes only on the Earth, where the main UV absorber is $\mathrm{O}_{2}$. The $\mathrm{O}_{2}$ photoabsorption cross sections are characterized by an accidental "window" at Lyman alpha $(1215.67 \AA)$ that allows solar photons to penetrate to altitudes of $\sim 75 \mathrm{~km}$; a discussion of this phenomenon can be found in any of numerous standard textbooks on aeronomy [e.g., Banks and Kockarts, 1973].

Additional supporting information may be found in the online version of this article.

${ }^{1}$ Department of Physics, Wright State University, Dayton, Ohio, USA.

${ }^{2}$ Department of Astronomy and Space Science, Chungnam National University, Daejeon, Korea.

${ }^{3}$ Department of Earth and Space Sciences, Chalmers University of Technology, Onsala, Sweden.

${ }^{4}$ Space Science Institute, Boulder, Colorado, USA.

Corresponding author: J. L. Fox, Department of Physics, Wright State University, Dayton, OH 45435, USA. (jane.fox@wright.edu)

(C)2013. American Geophysical Union. All Rights Reserved. 2169-9380/14/10.1002/2013JA019022
[3] Ionization by precipitation of very energetic particles is mostly confined to the auroral regions, which we do not consider here. We here model two mechanisms for production of low-altitude hydrocarbon ions at low to middle latitudes on Saturn. First, we model the direct ionization of hydrocarbon stable molecules and radicals by solar photons that penetrate to low altitudes in the wings and gaps of the $\mathrm{H}_{2}$ absorption lines between 842 and $1116 \AA$. In this wavelength region, $\mathrm{H}_{2}$ absorbs in discrete transitions, mostly in the Lyman $\left(B^{1} \Sigma_{u}^{+} ; v^{\prime} \leftarrow X^{1} \Sigma_{g}^{+} ; v^{\prime \prime}\right)$, the Werner $\left(C^{1} \Pi_{u}\right.$; $\left.v^{\prime} \leftarrow X^{1} \Sigma_{g}^{+} ; v^{\prime \prime}\right)$, and the Rydberg $\left(B^{\prime 1} \Sigma_{u}^{+} ; v^{\prime} \leftarrow X^{1} \Sigma_{g}^{+} ; v^{\prime \prime}\right)$ and $\left(D^{1} \Pi_{u} ; v^{\prime} \leftarrow X^{1} \Sigma_{g}^{+} ; v^{\prime \prime}\right)$ band systems. The absorption lines are very narrow, and the cross sections at the line centers are several orders of magnitude larger than those in the wings of the lines and those in the gaps between the clusters of lines. In order to compute the hydrocarbon photoionization rates, we have modeled the photoabsorption of $\mathrm{H}_{2}$ with very high resolution cross sections, of the order of $10^{-3} \AA$, and similarly high resolution solar fluxes. This resolution is sufficient to resolve the thermal Doppler-broadened line cores at any temperature above 10 K. Kim and Fox [1991, 1994] had previously shown that this mechanism produces a lower layer of hydrocarbon ions in the Jovian ionosphere. In the text that follows, the model constructed with the high spectral resolution $\mathrm{H}_{2}$ photoabsorption cross sections and solar fluxes will be referred to as the "high resolution model", and that constructed with low spectral resolution $\mathrm{H}_{2}$ cross sections and similarly low resolution solar fluxes will be referred to as the "low resolution model". The high 

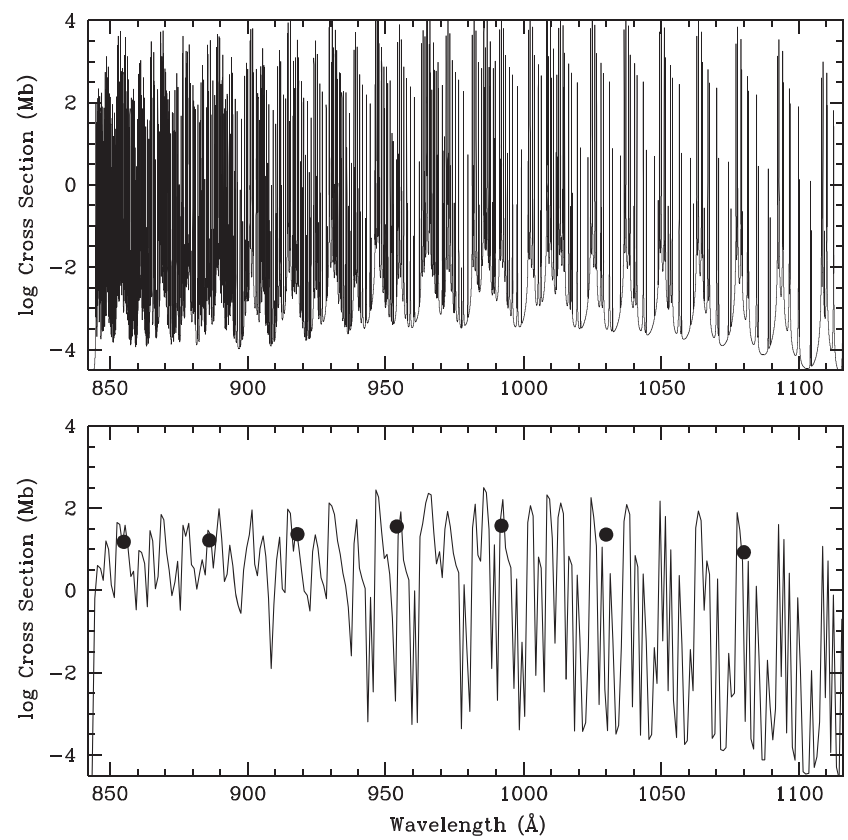

Figure 1. $\mathrm{H}_{2}$ photoabsorption cross sections in the 842 $1116 \AA$ region at $200 \mathrm{~K}$. (top) High spectral resolution cross sections constructed in this work. (bottom) Low resolution cross sections. These cross sections were constructed by averaging the high resolution cross sections over $1 \AA$ bins. Also shown as large dots are the very low resolution cross sections measured by Backx et al. [1976], which have been used in many investigations of the ionospheres of the outer planets.

resolution cross sections are temperature dependent. Those from 842 to $1116 \AA$ at a temperature of $200 \mathrm{~K}$ are shown in Figure 1 (top). These cross sections are averaged over $1 \AA$ bins, and the resulting cross sections are shown in Figure 1 (bottom). The cross sections of Backx et al. [1976] are given at $30-40 \AA$ intervals and are shown as large points on the lower plot. We note that most researchers use the very low resolution cross sections of Backx et al. [1976], while "low" spectral resolution here denotes a resolution of $1 \AA$. Previous studies of high resolution cross sections and their effects on ionospheres/thermospheres include those of Lavvas et al. [2011] for $\mathrm{N}_{2}$ on Titan and of Fox and Black [1989] for CO on Venus.

[4] The second mechanism we consider here for production of hydrocarbon ions is the photoionization by solar soft and harder X-rays in the wavelength region below $\sim 150 \AA$ and subsequent ionization by the concomitant very energetic photoelectrons, secondary, and Auger electrons. For the particular model that we have employed here, the two sources described above are found to maximize roughly in the same altitude range. This may not be the case for other Saturn models, where the homopause is found at different pressure levels.

[5] Previous models of hydrocarbon ions on Saturn have neglected $\mathrm{H}_{2}$ line absorption and were based on lower resolution $\mathrm{H}_{2}$ cross sections that allow fewer photons to penetrate to the region below the methane homopause. A few investigators have, however, included ionization by soft $\mathrm{X}$-rays and their photoelectrons and secondary electrons.
In order to provide context for our study, we present below a short review of measurements and models of the Saturn ionosphere, followed by a review of studies of hydrocarbon ions.

\subsection{Measurements and Models of the Saturn Ionosphere}

[6] Reviews of measurements and models of the ionosphere/thermosphere of Saturn have been presented by, for example, Majeed et al. [2004] and Witasse et al. [2008]. Nagy et al. [2009] have summarized the observations of the ionosphere of Saturn up to 2009 and the various models that were constructed between 1973 and 2009. Prior to Cassini, most of the information about the Saturn ionosphere was in the form of six radio occultation (RO) profiles, measurements of Saturn electrostatic discharges (SEDs), and intensities of the infrared emissions from $\mathrm{H}_{3}^{+}$. The latter emissions were found to be highly variable and largely confined to the auroral ovals, with only a few percent arising from lower latitudes [e.g., Stallard et al., 1999; Melin et al., 2007].

[7] SEDs are impulsive radio bursts, the transmission of which is assumed to be indicative of the peak electron density at various local times. The detection of SEDs by Kaiser et al. [1984] suggested that the diurnal variation of the peak from noon to midnight was 2 orders of magnitude, from $\sim 10^{5} \mathrm{~cm}^{-3}$ to $\sim 10^{3} \mathrm{~cm}^{-3}$, with dawn and dusk values of $\sim 10^{4} \mathrm{~cm}^{-3}$. The measurements of the diurnal variation of the electron density peak are reproduced here in Figure 2. Fischer et al. [2011] have more recently reported the incidence of SEDs detected from 2004 to 2009 and their local time behavior. They found that SEDs were highly variable but exhibited a somewhat smaller diurnal variation of 1 to 2 orders of magnitude, with noon values of the peak electron density of $(1-4) \times 10^{5} \mathrm{~cm}^{-3}$, midnight values of $(5-10) \times$ $10^{3} \mathrm{~cm}^{-3}$, and dawn and dusk values of $\sim 5 \times 10^{4} \mathrm{~cm}^{-3}$. The error bars on these values are, however, large.

[8] The Saturn ionosphere near the terminators has been probed by RO experiments on the flyby spacecraft Pioneer 11 [Kliore et al., 1980] and Voyagers 1 and 2 [e.g., Lindal et al., 1985]. The six electron density profiles that were returned from these spacecraft were highly structured and exhibited widely different characteristics for various latitudes and local times. The electron densities of the upper ionospheric peaks were of the order of $10^{4} \mathrm{~cm}^{-3}$ between 1800 and $2500 \mathrm{~km}$ above the $1 \mathrm{bar}$ level. The Voyager 1 ingress profile showed well-defined peaks down to $\sim 500 \mathrm{~km}$.

[9] Recently, the Cassini spacecraft has carried out RO measurements of the Saturn ionosphere, and the first 12 electron density profiles at low latitudes were published by Nagy et al. [2006]. The individual profiles show large variability in the peak altitudes, magnitudes, and vertical structure. Nagy et al. [2006] averaged the dawn and dusk profiles separately and found fairly large differences. These profiles are reproduced here as Figure 3. The averaged dawn profile showed smaller peak densities, of the order of $(1-2) \times$ $10^{3} \mathrm{~cm}^{-3}$ at altitudes of $\sim 2400 \mathrm{~km}$, while the averaged dusk profiles exhibited larger peak densities of $\sim(5-6) \times$ $10^{3} \mathrm{~cm}^{-3}$ near $1900 \mathrm{~km}$. Both sets of profiles showed multiple layers below the upper peak to $500-600 \mathrm{~km}$ above the 1 bar level. Some layering in the upper region of the ionosphere is also apparent. Nineteen more profiles from middle 


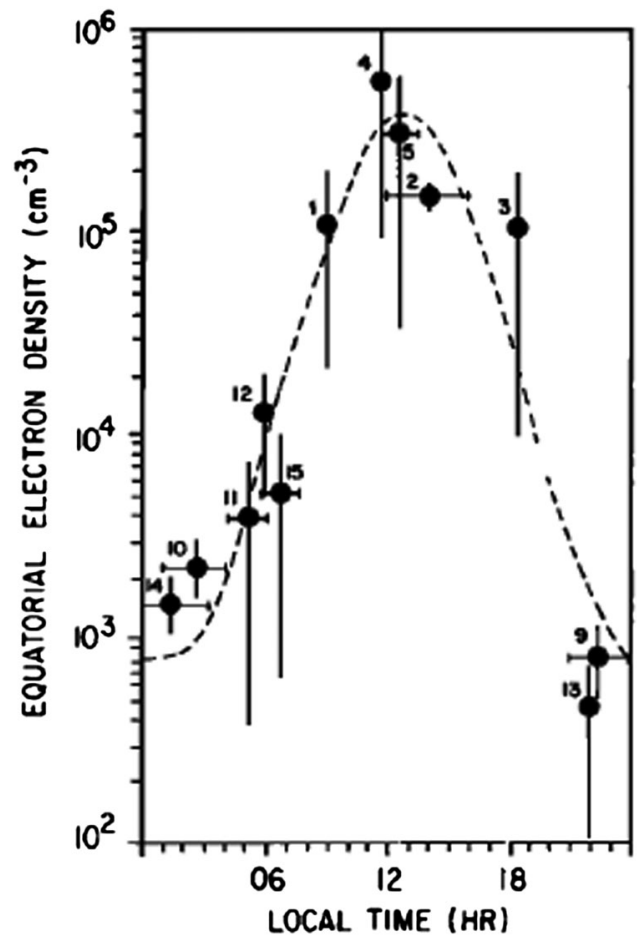

Figure 2. Equatorial peak electron densities as a function of local time obtained from Saturn electrostatic discharges. Maximum and minimum densities occur just after noon and midnight, respectively. The dashed line is a least squares fit to the data. Figure from Kaiser et al. [1984].

to high latitudes were published by Kliore et al. [2009]. These profiles clearly showed that the peak electron density increases with increasing latitude. A high degree of variability was observed, however, with peak electron densities ranging from $\sim 5 \times 10^{3}$ to $\sim 4 \times 10^{4} \mathrm{~cm}^{-3}$.

[10] Early models of the Saturn ionosphere, as well as those of Jupiter, had predicted peak $\mathrm{H}^{+}$and electron densities that were larger than those observed by at least an order of magnitude, with protons dominating the ionosphere over a large altitude range [e.g., McElroy, 1973]. In order to reduce the predicted densities of the long-lived protons photochemically, they must be converted to molecular ions, which are destroyed efficiently by dissociative recombination (DR) with ambient electrons. McElroy [1973] suggested that protons could be converted to molecular ions by reaction with vibrationally excited $\mathrm{H}_{2}(v \geq 4)$ :

$$
\mathrm{H}^{+}+\mathrm{H}_{2}(v \geq 4) \rightarrow \mathrm{H}_{2}^{+}+\mathrm{H}
$$

which is usually followed by

$$
\mathrm{H}_{2}^{+}+\mathrm{H}_{2} \rightarrow \mathrm{H}_{3}^{+}+\mathrm{H}
$$

$\mathrm{H}_{3}^{+}$ions are readily destroyed by DR

$$
\mathrm{H}_{3}^{+}+\mathrm{e} \rightarrow \mathrm{H}_{2}(v, \mathrm{~J})+\mathrm{H}
$$

or

$$
\mathrm{H}_{3}^{+}+\mathrm{e} \rightarrow \mathrm{H}+\mathrm{H}+\mathrm{H}
$$

Reaction (1) is usually assumed to proceed at gas kinetic rates, with rate coefficients in the range $(1-2) \times 10^{-9} \mathrm{~cm}^{3} \mathrm{~s}^{-1}$. Cross sections and/or rate coefficients for reaction (1) were recently computed by Ichihara et al. [2000] and by Krstić [2002]. Ichihara et al. reported high temperature rate coefficients in the range $\sim(1.2-1.8) \times 10^{-9} \mathrm{~cm}^{3} \mathrm{~s}^{-1}$. The fraction of $\mathrm{H}_{2}$ molecules in vibrational states $v \geq 4$ is, however, unknown. It is probable that the vibrational levels of $\mathrm{H}_{2}$ are not in local thermodynamic equilibrium (LTE) near or above the peak of the electron density layer. The distribution of vibrationally excited $\mathrm{H}_{2}$ in the atmosphere of Jupiter has been computed by Cravens [1987] and by Majeed et al. [1991] and reviewed by Yelle and Miller [2004]. The effects discussed for Jupiter are similar to those for Saturn.

[11] Connerney and Waite [1984] suggested that an influx of water from the rings could reduce the proton density by converting the $\mathrm{H}^{+}$ions into molecular ions, in such reactions as

$$
\mathrm{H}^{+}+\mathrm{H}_{2} \mathrm{O} \rightarrow \mathrm{H}_{2} \mathrm{O}^{+}+\mathrm{H}
$$

which is followed by reactions, such as

$$
\mathrm{H}_{2}+\mathrm{H}_{2} \mathrm{O}^{+} \rightarrow \mathrm{H}_{3} \mathrm{O}^{+}+\mathrm{H}
$$

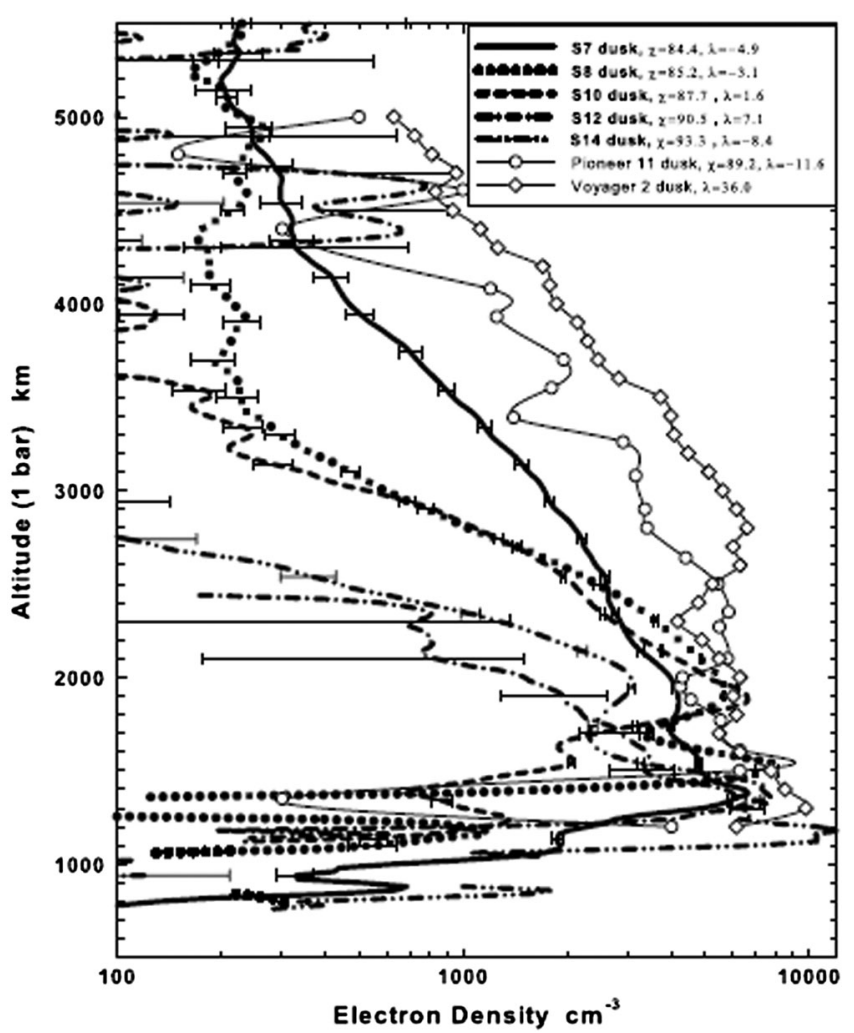

Figure 3. Weighted averages of dawn and dusk electron density profiles from 14 radio occultation measurements made by Cassini. The solar zenith angle range is from 84 to $96^{\circ}$ at near equatorial latitudes. Figure from Nagy et al. [2006]. 
A rich chemistry of oxygen-containing species is produced by this influx of water [e.g., Moses and Bass, 2000]. The water influx into the Saturn atmosphere has recently been suggested to arise from the gaseous plume of Enceladus rather than from the rings [e.g., Waite et al., 2006; Hartogh et al., 2011].

[12] The focus of most of the studies since the publication of Connerney and Waite [1984] has been on the relative effects of the two suggested photochemical mechanisms for destruction of protons, reactions (1) and (3), and on the role of dynamical processes such as magnetic field-aligned ion drift, which can act to raise or lower the altitude of the ion density peak [e.g., Majeed and McConnell, 1991, 1996; Moore et al., 2004, 2006, 2007, 2008, 2009, 2010, 2012; Müller-Wodarg et al., 2012].

[13] The vibrational distribution of $\mathrm{H}_{2}(v)$ in the ionosphere of Saturn was computed by Majeed et al. [1991], who included as sources of vibrational excitation fluorescence of $\mathrm{H}_{2}$ in the Lyman and Werner band systems that are excited by photons or electrons, DR of $\mathrm{H}_{3}^{+}$(reaction (3a)) and vibrational excitation of $\mathrm{H}_{2}$ by photoelectron impact. Loss processes for vibrationally excited $\mathrm{H}_{2}(v)$ included VT (vibration-translation) transfer of $\mathrm{H}_{2}(v)$ to $\mathrm{H}$ and to $\mathrm{H}_{2}$, and VV (vibration-vibration) transfer from $\mathrm{H}_{2}(v)$ to $\mathrm{H}_{2}$. Majeed et al. adopted a gas kinetic rate coefficient for reaction (1) of $2 \times 10^{-9} \mathrm{~cm}^{3} \mathrm{~s}^{-1}$ and reported profiles of effective vibrational temperatures in the Saturn ionosphere for each vibrational level up to $v=14$. The effective vibrational temperature $T_{v}$ at the electron density peak was found to be in the range $1800-2600 \mathrm{~K}$. This computed vibrational distribution was used in the model of Moore et al. [2004]. The calculations of Majeed et al. [1991] were, however, criticized later by Huestis [2005] and Huestis et al. [2008] as not including vibrational quenching of $\mathrm{H}_{2}(v)$ by protons, which is deemed to be as important as the charge transfer process. Hallett et al. [2005] have also presented other reactions that could be important in producing non-LTE effects in the vibrational distribution of $\mathrm{H}_{2}(v)$, including excitation of $\mathrm{H}_{2}(v)$ by collisions with energetic $\mathrm{H}$ atoms.

[14] Moses and Bass [2000] adopted the altitudedependent vibrational temperatures computed by Majeed et al. [1991], converted them into effective rate coefficients for reaction (1), and reported values that increased from $10^{-20} \mathrm{~cm}^{3} \mathrm{~s}^{-1}$ at $750 \mathrm{~km}$ to $10^{-13} \mathrm{~cm}^{3} \mathrm{~s}^{-1}$ at altitudes above $\sim 2200 \mathrm{~km}$. At the peak of the electron density profile for their standard model, which was found to occur at about $1200 \mathrm{~km}\left(10^{-6} \mathrm{mbar}\right)$, the effective value for $k_{1}$ was $\sim 3 \times$ $10^{-16} \mathrm{~cm}^{3} \mathrm{~s}^{-1}$.

[15] The effective rate coefficient for reaction (1) has often been assumed to be an adjustable parameter that is used to fit the $\mathrm{H}^{+}$peak density [e.g., Majeed and McConnell, 1991; Majeed and McConnell, 1996]. In the former study, effective rate coefficients of $10^{-16}, 10^{-15}$, and $10^{-14} \mathrm{~cm}^{3} \mathrm{~s}^{-1}$ were tested, and the best fit rate coefficient was found to be $7 \times 10^{-15} \mathrm{~cm}^{3} \mathrm{~s}^{-1}$. In some models, the altitude profile of $k_{1}$ of Moses and Bass [2000] has been varied by a constant factor over the entire altitude range to fit the $\mathrm{H}^{+}$profile. For example, in their time-dependent models, Moore et al. [2006, 2010, 2012] found that the best fit profile of the effective rate coefficient for reaction (1) was equal to 0.125 times that of Moses and Bass [2000].
[16] With three essentially free parameters: the effective value of $k_{1}$, the rate of water influx, and ion drifts along field lines, it is possible to fit a wide range of electron density profiles at Saturn. For example, Moore et al. [2006] found that with sufficient influx of water, the value of $k_{1}$ could be reduced considerably. The diurnal variation in the peak electron density that is indicated by the detection of SEDs has, however, not been reproduced [e.g., Majeed and McConnell, 1996; Moses and Bass, 2000; Moore et al., 2004, 2006, 2012].

[17] Nonetheless, recent models of the ionosphere of Saturn have suggested that beneath the topside proton transport-dominated region, there are two photochemically produced regions: one in which the major ion is $\mathrm{H}_{3}^{+}$and one that appears at lower altitudes in which hydrocarbon ions dominate. The electron density profiles measured by RO experiments sometimes show sharp layers, the chemical identity of which is unknown [e.g, Kliore et al., 2009; Nagy et al., 2009]. Nearly all parts of the ionosphere near and below the peak region show some layering sometimes, which may be caused by gravity waves [e.g., Matcheva et al., 2001; Matcheva and Barrow, 2012]. Wind shears can cause layering of metal atoms, as shown by Lyons et al. [1992] and Moses and Bass [2000]. Although it is usually suggested that the longer-lived atomic ions react to gravity waves or wind shears by forming layers, evidence of wave activity can also be seen in the Martian electron density profiles that were returned from the Mars Global Surveyor Radio Science experiment [e.g., Hinson and Simpson, 2008; cf., Fox and Weber, 2012]. The dominant ion near the peak of the Martian electron density profiles is a molecular ion, $\mathrm{O}_{2}^{+}$[e.g., Hanson et al., 1977].

\subsection{Hydrocarbon Ions on Saturn}

[18] Probably the most cited source of $\mathrm{H}_{2}$ photoabsorption cross sections in the wavelength range $842-1116 \AA$ is that of Backx et al. [1976]. Their cross sections are given at 0.5 to $2 \mathrm{eV}$ intervals or about $30-40 \AA$ in this wavelength range. Values from $\sim 1.8 \times 10^{-18}$ to $\sim 3.7 \times 10^{-17} \mathrm{~cm}^{2}$ have been reported, as shown in Figure 1.

[19] The chemistry of the hydrocarbon ion layer has received little attention. Following a suggestion by McElroy [1973], Atreya and Donahue [1975] first modeled the hydrocarbon ion chemistry in the ionosphere of Saturn but included only photoionization and photoelectron-impact ionization of the major species: $\mathrm{H}, \mathrm{H}_{2}$, and He. Hydrocarbon ions were produced by charge transfer and dissociative charge transfer of $\mathrm{H}^{+}, \mathrm{H}_{3}^{+}$, and $\mathrm{He}^{+}$to $\mathrm{CH}_{4}$. These reactions were assumed to produce only $\mathrm{C}_{1}$-containing ions, and subsequent reactions of these ions with the major neutral species eventually formed the terminal ion $\mathrm{C}_{2} \mathrm{H}_{5}^{+}$. Atreya and Donahue [1975] predicted a small peak density of $\mathrm{C}_{2} \mathrm{H}_{5}^{+}$ions of about $4 \times 10^{2} \mathrm{~cm}^{-3}$ beneath the upper peak of $\mathrm{H}^{+}$ions, which were characterized by a density of $10^{5} \mathrm{~cm}^{-3}$. Many subsequent models have either ignored hydrocarbon ions altogether [e.g., Majeed and McConnell, 1991, 1996] or adopted the assumptions of Atreya and Donahue [1975] in their models [e.g., Moore et al., 2004, 2006].

[20] Among the early models of Saturn, only Waite et al. [1979] and Waite [1981] included the direct ionization of methane by photons and photoelectrons, and ionization of 


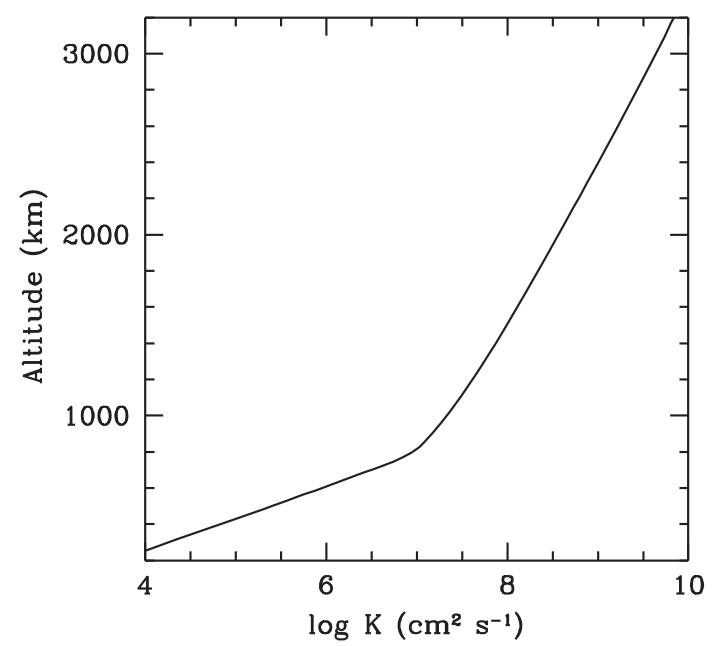

Figure 4. Eddy diffusion coefficient profile from about $400 \mathrm{~km}$ to $3200 \mathrm{~km}$. From Moses and Vervack Jr. [2006].

$\mathrm{CH}_{3}$ by Lyman alpha in their predictions of the altitude profiles of hydrocarbon ions. The predicted terminal ion was $\mathrm{C}_{2} \mathrm{H}_{5}^{+}$, and its peak density was, however, small, in the range $\sim 2 \times 10^{2}$ to $1 \times 10^{3} \mathrm{~cm}^{-3}$.

[21] In their model of the Saturn ionosphere, Moses and Bass [2000] included complete hydrocarbon ion chemistry up to the $\mathrm{C}_{4}$ level with generic ions $\mathrm{C}_{5} \mathrm{H}_{x}^{+}$and $\mathrm{C}_{6} \mathrm{H}_{x}^{+}$representing higher hydrocarbon ions. Most of their photoabsorption cross sections were characterized by low spectral resolution, although they included ionization of hydrocarbons by four solar lines, including those at 923.1, 933.4, 949.7, and $977 \AA$.

[22] Galand et al. [2009; cf., Moore et al., 2008, 2010, 2012] focused on the effects of photoelectrons and secondary ions on the ionization profiles but included only photo- and electron-impact ionizations of methane as the initial source of hydrocarbon ions. The hydrocarbon ion chemistry in this model is limited to $\mathrm{C}_{1}$-ions. Furthermore, the photoabsorption and photoionization cross sections that are shown in the paper are almost structureless. For the wavelength region longward of the $\mathrm{H}_{2}$ ionization threshold, these authors adopted the $\mathrm{H}_{2}$ photoabsorption cross sections of Backx et al. [1976]. In addition, the spectral resolution of their solar flux model was $10 \AA$, which made capturing the discrete line spectrum of $\mathrm{H}_{2}$ impossible.

\section{Modeling Approach}

[23] The major constituents in the thermosphere of Saturn are $\mathrm{H}_{2}, \mathrm{He}, \mathrm{H}$, and $\mathrm{CH}_{4}$. The abundance of $\mathrm{CH}_{4}$ drops off rapidly above the homopause, which is defined here as the altitude where the methane molecular diffusion coefficient is equal to the eddy diffusion coefficient. Stable hydrocarbon molecules are insignificant species in the upper thermosphere of Saturn but are found in abundance below the methane homopause, which is observed to vary greatly with latitude and time [e.g., Kliore et al., 2009; Nagy et al., 2009]. For this study, we have adopted a model from Moses and Vervack Jr. [2006] that was developed to reproduce the Voyager 1 egress solar occultation data. The abstract for this model can be found at the website www.lpi.usra.edu/ meetings/lpsc2006/pdf/1803.pdf. This model is characterized by a latitude of $27^{\circ} \mathrm{S}$, a magnetic dip angle of $45.5^{\circ}$, and a homopause altitude of $1010 \mathrm{~km}$, which corresponds to a pressure level of $4 \times 10^{-2} \mu$ bar. A plot of the eddy diffusion coefficient as a function of altitude is shown in Figure 4. We have assumed here a local time of noon; therefore, the solar zenith angle (SZA) is $27^{\circ}$. The range of the model is from $400 \mathrm{~km}$ to $4000 \mathrm{~km}$ (120 to $2.6 \times 10^{-8} \mu$ bar), and the altitude grid size is $10 \mathrm{~km}$. All of the altitudes quoted here are referred to the 1 bar level for this particular model; pressure levels are quoted along with the altitudes, which, because of the oblate shape of the planet, vary with latitude. Lindal et al. [1985] have shown values for the radius of Saturn at the $100 \mathrm{mb}$ level as a function of latitude, labeled with the latitudes of the radio occultations for the various pre-Cassini missions.

[24] The background atmosphere consists of fixed density profiles of 18 neutral species, including $\mathrm{H}_{2}, \mathrm{He}, \mathrm{CH}_{4}$, $\mathrm{C}_{2} \mathrm{H}_{2}, \mathrm{C}_{2} \mathrm{H}_{4}, \mathrm{C}_{2} \mathrm{H}_{6}, \mathrm{CH}_{3}, \mathrm{CH}_{3} \mathrm{C}_{2} \mathrm{H}, \mathrm{H}_{2} \mathrm{O}, \mathrm{CO}, \mathrm{C}, \mathrm{CH}, \mathrm{C}_{2}, \mathrm{O}$, $\mathrm{O}_{2}, \mathrm{CO}_{2}, \mathrm{H}_{2} \mathrm{CO}$, and $\mathrm{CH}_{3} \mathrm{OH}$, which, along with the neutral temperature and eddy diffusion coefficient profiles, are adopted from the model of Moses and Vervack Jr. [2006]. In Figure 5, we present the altitude profiles of the densities of the most important neutral species, which include $\mathrm{H}, \mathrm{H}_{2}$, and $\mathrm{He}$; the stable hydrocarbon molecules methane, ethane, acetylene, and ethylene; the radical $\mathrm{CH}_{3}$; and water. We have compiled from the literature the photoionization and photodissociation cross sections for the fixed neutral species and $\mathrm{H}$ over the 1-2000 $\AA$ range. The sources of these cross sections can be found in the supporting information of this paper. The electron temperatures are adapted from the calculations of Moore et al. [2008] for noon conditions, and the ratios of the values of $T_{e}$ are assumed to be the same as the ratios of $T_{n}$ in their model and ours. The resulting

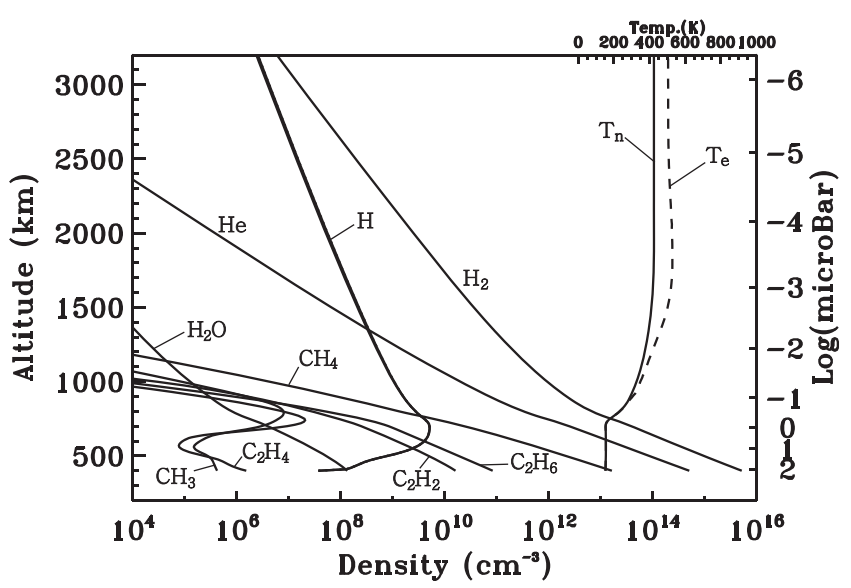

Figure 5. Altitude profiles for the densities of the major neutral species and neutral and electron temperatures in the thermosphere/mesosphere of Saturn from the model of Moses and Vervack Jr. [2006]. The altitudes are those above the 1 bar level of the atmosphere. The model is characterized by a latitude of $27^{\circ} \mathrm{S}$ and a magnetic dip angle of $45.5^{\circ}$. The densities of these background species are assumed to be fixed, except for those of $\mathrm{H}$, which were computed selfconsistently in the model. The electron temperature profile, which is shown as a dashed profile, is based on the model of Moore et al. [2008]. 
electron temperature profile increases with altitude to a value of $\sim 500 \mathrm{~K}$ at the top of the model.

[25] For the high resolution model, we have constructed photoabsorption cross sections of $\mathrm{H}_{2}$ over the wavelength range $842-1116 \AA$ with a resolution of $0.001 \AA$, using the transition probabilities for rovibrational lines in the $\mathrm{H}_{2}$ Lyman $(B-X)$, Werner $(C-X)$, and Rydberg $\left(B^{\prime}-X\right)$ and $(D-X)$ band systems computed by Abgrall et al. [2000]. In this wavelength range, the photoionization and photodissociation cross sections of the other main species were also interpolated to $0.001 \AA$ resolution. We have assumed, in this preliminary model of fluorescent scattering, that the $\mathrm{H}_{2}$ vibrational distribution is in LTE at the local neutral temperature. It is likely that LTE is not valid at the higher altitudes [e.g., Shemansky and Liu, 2012].

[26] We have constructed a low solar activity solar spectrum at a resolution of $0.001 \AA$ from that measured by SOHO/Solar Ultraviolet Measurements of Emitted Radiation (SUMER) in the wavelength range of 842-1116 $\AA$ for the quiet solar disk [Curdt et al., 2001]. The total photon flux in this region of the spectrum was scaled to that of the SOLAR2000 (S2K) v2.22 76200 spectrum, which pertains to 18 July 1976 [e.g., Tobiska, 2004], so that the total solar photon fluxes in the $842-1116 \AA$ range are the same for the low and high resolution models. The low resolution $\mathrm{H}_{2}$ cross sections in the range $842-1116 \AA$ were not taken from experiments; they were computed by averaging the high resolution cross sections over $1 \AA$ bins. The spectrum for the wavelength ranges outside that of the high resolution cross sections was adopted in "Hinteregger" format: that is, with $1 \AA$ resolution in the continua and as delta functions at the strong solar lines [e.g. Hinteregger et al., 1981]. For the spectral region from $400 \AA$ to $841 \AA$ and that from 1116 to $2000 \AA$, we have adopted the solar fluxes from the S2K v2.22 76200 spectrum. For the fluxes of photons with wavelengths smaller than $400 \AA$, we have adopted the Thermosphere Ionosphere Mesosphere Energetics and Dynamics satellite (TIMED)/Solar EUV Explorer (SEE) XUV Photon Spectrometer (XPS) level 4 spectrum for 21 June 2008 for which F10.7 = 64.8 [Woods et al., 2008]. The XPS spectra that we use are characterized by $1 \AA$ resolution between 0 and $400 \AA$, and we have converted them to Hinteregger format. The photon fluxes of the XPS spectrum shortward of $100 \AA$ are smaller by about a factor of 5 than those in the S2K 76200 spectrum.

[27] We have included electron impact processes for seven species, including $\mathrm{H}_{2}, \mathrm{He}, \mathrm{H}, \mathrm{CH}_{4}, \mathrm{C}_{2} \mathrm{H}_{2}, \mathrm{C}_{2} \mathrm{H}_{4}$, and $\mathrm{C}_{2} \mathrm{H}_{6}$, the cross sections for which were obtained from our previous Jupiter models [e.g., Perry et al., 1999] and from a more recent literature search. The sources of these cross sections are given in the supporting information of this paper. We have assumed that photoelectrons deposit their energy locally, using a simple method that was described many years ago by Dalgarno and Lejeune [1971].

[28] We have compiled a set of rate coefficients for 749 reactions, including ion-neutral, neutral-neutral, and dissociative recombination reactions. These reactions involve 53 ions, including $\mathrm{H}^{+}, \mathrm{H}_{2}^{+}, \mathrm{He}^{+}, \mathrm{H}_{3}^{+}$, and $\mathrm{HeH}^{+}$; the hydrocarbon ions $\mathrm{C}^{+}, \mathrm{CH}^{+}, \mathrm{CH}_{2}^{+}, \mathrm{CH}_{3}^{+}, \mathrm{CH}_{4}^{+}, \mathrm{CH}_{5}^{+}, \mathrm{C}_{2}^{+}, \mathrm{C}_{2} \mathrm{H}^{+}, \mathrm{C}_{2} \mathrm{H}_{2}^{+}$, $\mathrm{C}_{2} \mathrm{H}_{3}^{+}, \mathrm{C}_{2} \mathrm{H}_{4}^{+}, \mathrm{C}_{2} \mathrm{H}_{5}^{+}, \mathrm{C}_{2} \mathrm{H}_{6}^{+}, \mathrm{C}_{2} \mathrm{H}_{7}^{+}, \mathrm{C}_{3} \mathrm{H}^{+}, \mathrm{C}_{3} \mathrm{H}_{2}^{+}, \mathrm{C}_{3} \mathrm{H}_{3}^{+}, \mathrm{C}_{3} \mathrm{H}_{4}^{+}$, $\mathrm{C}_{3} \mathrm{H}_{5}^{+}, \mathrm{C}_{3} \mathrm{H}_{6}^{+}, \mathrm{C}_{3} \mathrm{H}_{7}^{+}, \mathrm{C}_{3} \mathrm{H}_{8}^{+}, \mathrm{C}_{3} \mathrm{H}_{9}^{+}, \mathrm{C}_{4} \mathrm{H}^{+}, \mathrm{C}_{4} \mathrm{H}_{2}^{+}, \mathrm{C}_{4} \mathrm{H}_{3}^{+}, \mathrm{C}_{4} \mathrm{H}_{4}^{+}$, $\mathrm{C}_{4} \mathrm{H}_{5}^{+}, \mathrm{C}_{4} \mathrm{H}_{6}^{+}, \mathrm{C}_{4} \mathrm{H}_{7}^{+}, \mathrm{C}_{4} \mathrm{H}_{8}^{+}$, and $\mathrm{C}_{4} \mathrm{H}_{9}^{+}$; two generic hydrocar- bon ions $\mathrm{C}_{5} \mathrm{H}_{n}^{+}$and $\mathrm{C}_{6} \mathrm{H}_{n}^{+}$; the oxygen-bearing ions $\mathrm{O}^{+}, \mathrm{O}_{2}^{+}$, $\mathrm{HO}^{+}, \mathrm{H}_{2} \mathrm{O}^{+}, \mathrm{H}_{3} \mathrm{O}^{+}, \mathrm{CO}^{+}, \mathrm{CO}_{2}^{+}, \mathrm{HCO}^{+}, \mathrm{HOC}^{+}, \mathrm{HO}_{2}^{+}, \mathrm{CH}_{2} \mathrm{O}^{+}$, $\mathrm{CH}_{2} \mathrm{OH}^{+}, \mathrm{CH}_{3} \mathrm{OH}^{+}$, and $\mathrm{CH}_{3} \mathrm{OH}_{2}^{+}$; and a generic oxygenbearing ion $\mathrm{C}_{x} \mathrm{H}_{y} \mathrm{O}_{z}^{+}$for which $x$ and $z$ are greater than 1 . Twenty-five neutral species are included in the chemical reactions: the eighteen fixed background species and seven radicals, including $\mathrm{H},{ }^{1} \mathrm{CH}_{2},{ }^{3} \mathrm{CH}_{2}, \mathrm{C}_{2} \mathrm{H}, \mathrm{C}_{2} \mathrm{H}_{3}, \mathrm{C}_{2} \mathrm{H}_{5}$, and $\mathrm{OH}$. The latter seven species are computed self-consistently in the model. Photochemical equilibrium is assumed at the bottom boundary at $400 \mathrm{~km}$, except for $\mathrm{H}$, which is fixed to the number density in the model of Moses and Vervack $J r$. [2006]. At the top boundary, zero flux is assumed for all species.

[29] The neutral-neutral rate coefficients were adopted from the University of Manchester Institute of Science and Technology (UMIST) database [Woodall et al., 2007]. The rate coefficients for most of the ion-neutral reactions were adopted from the compilation of Anicich [2003]. There have been several recent studies of hydrocarbon ion-molecule reactions motivated by studies of the lower ionosphere of Titan, and we have adopted these recently measured rate coefficients, about 50 of which have been compiled by Anicich et al. [2005]. These rate coefficients can all be found in the literature, and we do not repeat them here. Most of the dissociative recombination coefficients, except that for $\mathrm{H}_{3}^{+}$, have been taken from the review of Florescu-Mitchell and Mitchell [2006]. The DR coefficient of $\mathrm{H}_{3}^{+}$ has been the subject of many conflicting studies, which have been reviewed by Johnsen and Guberman [2010]. We have adopted the value from Pagani et al. [2009] of $6.8 \times$ $10^{-8}\left(300 / T_{e}\right)^{0.52} \mathrm{~cm}^{3} \mathrm{~s}^{-1}$. For the generic ions $\mathrm{C}_{5} \mathrm{H}_{n}^{+}, \mathrm{C}_{6} \mathrm{H}_{n}^{+}$, and $\mathrm{C}_{x} \mathrm{H}_{y} \mathrm{O}_{z}^{+}$, we have adopted DR coefficients of $3.5 \times$ $10^{-7}\left(300 / T_{e}\right)^{0.5} \mathrm{~cm}^{3} \mathrm{~s}^{-1}$.

[30] The reaction set, like those applied to the Titan ionosphere, is more or less complete for hydrocarbon ions containing up to four carbon atoms [e.g., Keller et al., 1998; Banaszkiewicz et al., 2000; Wilson and Atreya, 2004; Vuitton et al., 2009; Cui et al., 2009]. Even this reaction set is not exhaustive, however, since hydrocarbon ions with four or more carbon atoms may have several isomers, including straight or branching chains and cyclic and noncyclic structures. The hydrocarbon ions whose densities we have calculated here most likely will continue to react with ambient hydrocarbons, forming higher hydrocarbon ions. The total density of hydrocarbon ions will, however, probably not be much affected by this process.

\section{Results and Discussion}

[31] In Figure 6, we present the altitudes for optical depth unity for wavelengths from 1 to about $1500 \AA$ for the high resolution model. The apparently "solid" section of this figure, from about 842 to $1116 \AA$, is the region where the depth of penetration of photons, which is determined by the photoabsorption of $\mathrm{H}_{2}$, is highly oscillatory, and the altitude of penetration ranges from $\sim 700$ to about $3400 \mathrm{~km}$, which corresponds to a pressure range of about $0.88 \mu$ bar to $2.2 \times 10^{-7} \mu$ bar. Some of the solar photons in the range 842 to $1116 \AA$, including the strong C III line at $977.02 \AA$, the $\mathrm{O}$ VI line at $1031.91 \AA$, and part of the continuum, penetrate to below the methane homopause, resulting in significant photoionization of hydrocarbons and $\mathrm{H}$. Solar photons shortward of $842 \AA$ are absorbed mostly by the $\mathrm{H}_{2}$ continuum, 


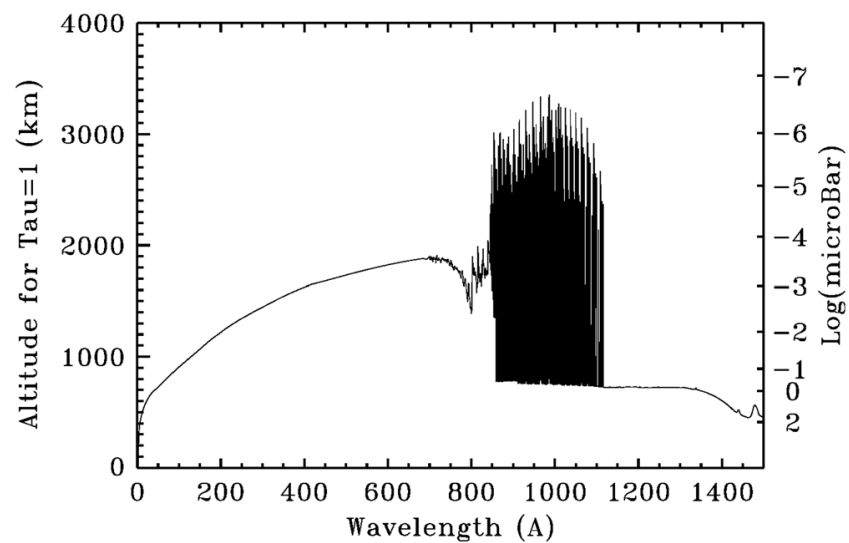

Figure 6. Altitude of unit optical depth for the wavelength range of 1 to $1500 \AA$ for the high resolution model, which is characterized by a solar zenith angle of $27^{\circ}$. The oscillations in the 842 to $1116 \AA$ range are characteristic of the high resolution photoabsorption cross sections of $\mathrm{H}_{2}$. Soft $\mathrm{X}$-rays with wavelengths of $\sim 40-150 \AA$ can be seen to be absorbed between 700 and $1000 \mathrm{~km}$.

and those longward of $1116 \AA$ are absorbed by methane and other hydrocarbons. Lyman alpha photons penetrate to about $700 \mathrm{~km}$ ( $\sim 0.88 \mu \mathrm{bar})$, and soft X-rays are absorbed between 700 and $1000 \mathrm{~km}$. The harder X-rays, defined here as those shortward of the Auger threshold of C, $\sim 40 \AA$ penetrate below $700 \mathrm{~km}$ due to the very small photoabsorption cross sections of $\mathrm{He}$ and $\mathrm{H}_{2}$ at these wavelengths [e.g., Yan et al., 1998].

[32] In Figure 7a, we present production rate profiles of $\mathrm{H}^{+}, \mathrm{H}_{2}^{+}$, and $\mathrm{He}^{+}$due to photoionization of their parent neutrals as functions of altitude and pressure for both the high and low resolution models. Also shown are altitude and pressure profiles for photodissociation and photodissociative ionization of $\mathrm{H}_{2}$. Only the photoionization profile of $\mathrm{H}$ and the photodissociation profile of $\mathrm{H}_{2}$, which are shown as solid and dotted curves, are different for the high and low resolution models. The profiles for photoionization of $\mathrm{H}$ for the low and high resolution models differ greatly because ionizing photons in the 842-911 $\AA$ range penetrate deeper into the thermosphere in the high resolution model. In the low resolution model, the peak in the $\mathrm{H}^{+}$production rate appears near $2000 \mathrm{~km}\left(\sim 1.5 \times 10^{-4} \mu \mathrm{bar}\right)$, with a magnitude of about $4 \times 10^{-2} \mathrm{~cm}^{-3} \mathrm{~s}^{-1}$; in the high resolution model, the $\mathrm{H}^{+}$production rate peaks much lower, near $830 \mathrm{~km}(0.2 \mu \mathrm{bar})$, with a magnitude of about $1 \mathrm{~cm}^{-3} \mathrm{~s}^{-1}$. This value is larger by several orders of magnitude than the production rate of $\mathrm{H}^{+}$at the same altitude in the low resolution model. The altitude profiles for photodissociation of $\mathrm{H}_{2}$ differ substantially for the high and low resolution models, because absorption of photons in the 842-1116 $\AA$ range only leads to dissociation when the photons are emitted to the continua of the excited states, in the so-called "spontaneous radiative dissociation" [e.g., Dalgarno and Stevens, 1970]. Figure 1 shows that our low resolution $\mathrm{H}_{2}$ photoabsorption cross sections, which were constructed by averaging the high resolution cross sections over $1 \AA$, still show significant oscillatory structure, with peaks and troughs that vary over 1 to 4 orders of magnitude, compared to 7 to 8 orders of magnitude for the high resolution cross sections. By contrast, the measured cross sections of Backx et al. [1976] vary by factors of only about 20 over this region.

[33] In Figure $7 \mathrm{~b}$, we compare the predicted production rate profiles of $\mathrm{CH}_{4}^{+}, \mathrm{C}_{2} \mathrm{H}_{2}^{+}, \mathrm{C}_{2} \mathrm{H}_{4}^{+}, \mathrm{C}_{2} \mathrm{H}_{6}^{+}$, and $\mathrm{CH}_{3}^{+}$due to photoionization of hydrocarbons as a function of altitude and pressure for the two models. In the high resolution model, the production rate of $\mathrm{CH}_{4}^{+}$peaks near $760 \mathrm{~km}$ $(0.36 \mu$ bar $)$ with a rate of $2.3 \mathrm{~cm}^{-3} \mathrm{~s}^{-1}$, whereas for the low resolution model, the peak is a factor of 22 smaller. Except for $\mathrm{CH}_{3}^{+}$, which is produced mainly by photoionization of $\mathrm{CH}_{3}$ by Lyman alpha photons, the production rates of the other hydrocarbon ions are also considerably larger in the high resolution model than in the low resolution model.

[34] In Figure 8, we present altitude profiles of the rates of electron impact ionization of $\mathrm{H}_{2}, \mathrm{H}, \mathrm{He}$, and hydrocarbons, along with electron impact dissociation and dissociative ionization of $\mathrm{H}_{2}$. The profiles for ionization, dissociative
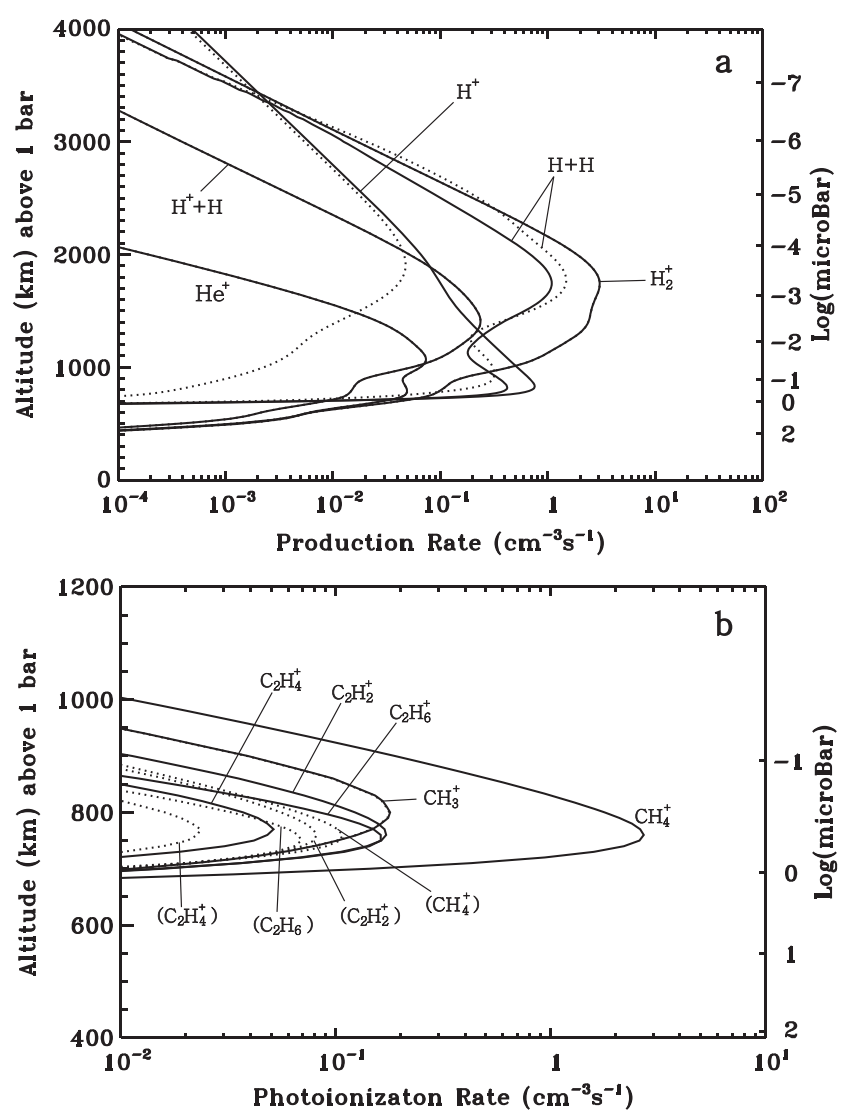

Figure 7. (a) Altitude profiles of the rates of photoionization of $\mathrm{H}, \mathrm{H}_{2}$, and $\mathrm{He}$ and rates of photodissociative ionization and photodissociation of $\mathrm{H}_{2}$ computed using the high resolution model are shown with solid curves. The production rate profiles of $\mathrm{H}^{+}$and $\mathrm{H}$ for the low resolution model are shown with dotted curves for comparison. (b) Altitude profiles of the production rates of the major hydrocarbon ions by photoionization of hydrocarbons for the high resolution model are shown with solid curves. The production rates computed with the low resolution model are shown as dotted curves for comparison. Note that the production rate of $\mathrm{CH}_{4}^{+}$is larger by a factor of $\sim 22$ for the high resolution model as compared to that of the low resolution model. The solar zenith angle is $27^{\circ}$. 


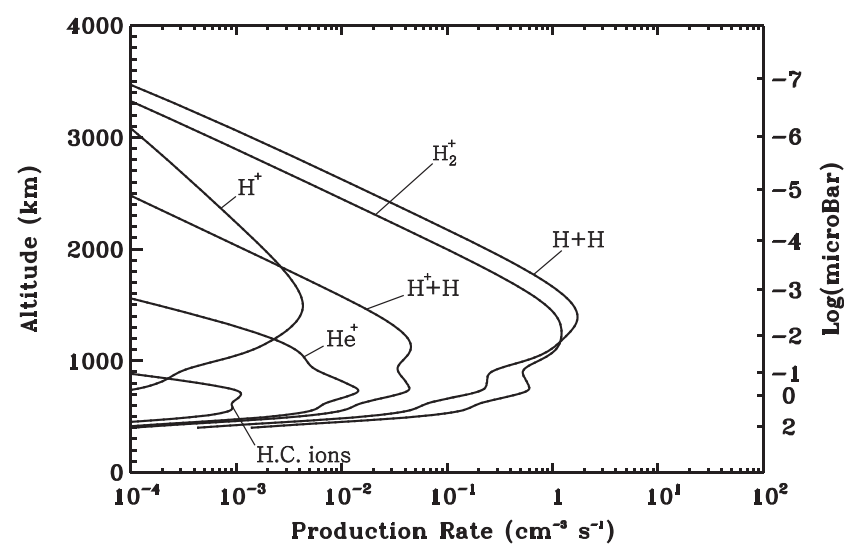

Figure 8. Altitude profiles of the production rates of various species due to electron impact ionization of $\mathrm{H}_{2}, \mathrm{H}$, and hydrocarbons, and electron impact dissociative ionization and dissociation of $\mathrm{H}_{2}$. The lower peaks are due to the energetic electron impact ionization that accompanies the penetration of soft X-rays into the Saturnian lower thermosphere. The label "H. C. ions" refers to production of hydrocarbon ions by energetic electron impact. The solar zenith angle is $27^{\circ}$.

ionization, and dissociation of $\mathrm{H}_{2}$ exhibit two peaks. The upper peak near $1500 \mathrm{~km}\left(2 \times 10^{-3} \mu\right.$ bar $)$ is that associated with photoelectrons produced by ionization of the major thermospheric species by EUV photons with wavelengths longward of $\sim 200 \AA$. The lower peaks near $750 \mathrm{~km}(0.42 \mu$ bar $)$ arise from ionization of the major species by the more energetic electrons that are produced subsequent to absorption of soft X-ray photons with wavelengths in the range $\sim 40-150 \AA$. The peak of the direct electron-impact ionization rate profile of hydrocarbons is very small and appears near $700 \mathrm{~km}$ $\left(0.88 \mu\right.$ bar) with a magnitude of about $10^{-3} \mathrm{~cm}^{-3} \mathrm{~s}^{-1}$. The direct production rate of hydrocarbon ions reflects both the small densities of the hydrocarbons and the small X-ray fluxes that characterize our low solar activity model. X-ray fluxes can increase by orders of magnitude on time scales of minutes to hours following solar flares, which are more common at higher solar activity. For electron impact ionization, the high and low resolution models do not differ, because photons in the $842-1116 \AA$ region do not produce photoelectrons that are capable of further ionization.

[35] Even though hydrocarbon ions are not produced in significant amounts from direct electron impact ionization, they are produced in abundance by chemical reactions of neutral hydrocarbons with the ions produced by electron impact ionization of the major species, including $\mathrm{H}_{2}, \mathrm{He}$, and $\mathrm{H}$ and by photoionization of $\mathrm{H} \mathrm{H}_{2}^{+}$is the major species produced, but over most of the thermosphere, it reacts immediately with $\mathrm{H}_{2}$ to form $\mathrm{H}_{3}^{+}$(reaction (2)). Hydrocarbon ions are produced in reactions of $\mathrm{H}_{3}^{+}, \mathrm{H}^{+}$, and $\mathrm{He}^{+}$with hydrocarbon neutrals below the homopause, such as

$$
\begin{gathered}
\mathrm{H}_{3}^{+}+\mathrm{CH}_{4} \rightarrow \mathrm{CH}_{5}^{+}+\mathrm{H}_{2}, \\
\mathrm{H}_{3}^{+}+\mathrm{C}_{2} \mathrm{H}_{4} \rightarrow \mathrm{C}_{2} \mathrm{H}_{5}^{+}+\mathrm{H}_{2}, \\
\mathrm{H}_{3}^{+}+\mathrm{C}_{2} \mathrm{H}_{2} \rightarrow \mathrm{C}_{2} \mathrm{H}_{3}^{+}+\mathrm{H}_{2},
\end{gathered}
$$

$$
\begin{gathered}
\mathrm{H}^{+}+\mathrm{CH}_{4} \rightarrow \mathrm{CH}_{4}^{+}+\mathrm{H}, \\
\mathrm{H}^{+}+\mathrm{CH}_{4} \rightarrow \mathrm{CH}_{3}^{+}+\mathrm{H}_{2}, \\
\mathrm{He}^{+}+\mathrm{CH}_{4} \rightarrow \mathrm{CH}_{3}^{+}+\mathrm{H}+\mathrm{He}, \\
\mathrm{He}^{+}+\mathrm{CH}_{4} \rightarrow \mathrm{CH}_{2}^{+}+\mathrm{H}_{2}+\mathrm{He} .
\end{gathered}
$$

In Figure 9, we present altitude profiles of the rates of these reactions and a profile that represents the sum of all the reactions that are primary production mechanisms for hydrocarbon ions. These reactions are accompanied by many other reactions that transform hydrocarbon ions into other, usually larger hydrocarbon ions. By comparing Figures $7 \mathrm{~b}$ and 9, we see that production of hydrocarbon ions due to direct ionization of the parent neutrals peaks near $760 \mathrm{~km}$ with a value that is larger by a factor $\sim 1.6$ than that of reactions that represent primary production of hydrocarbon ions. Below the hydrocarbon photoionization peak, these reactions are, however, more important than direct photoionization, and the production profile forms a broad shoulder that extends down to $400 \mathrm{~km}$, the lower boundary of the model.

[36] In Figure 10a, we show altitude and pressure profiles of the densities of the most important non-hydrocarbon ions for both the high resolution and the low resolution models. The density profile of the major ion $\mathrm{H}^{+}$peaks near $1900 \mathrm{~km}$ $\left(1.5 \times 10^{-4} \mu\right.$ bar $)$ with a magnitude of $5 \times 10^{4} \mathrm{~cm}^{-3}$ for the high resolution model.

[37] A calculation of the vibrational distribution of $\mathrm{H}_{2}(v)$, which determines the importance of reaction (1), is beyond the scope of this study. With the substantial water influx that is in the model, we have assumed that the vibrational distribution is such that the effective rate coefficient for this reaction is $1 \times 10^{-16} \mathrm{~cm}^{3} \mathrm{~s}^{-1}$. The predicted peak $\mathrm{H}^{+}$density is sensitive to larger values of $k_{1}$ but not to smaller values; the predicted $\mathrm{H}^{+}$peak density is indistinguishable from that for a rate coefficient of $10^{-20} \mathrm{~cm}^{3} \mathrm{~s}^{-1}$. This will probably not be the case for smaller assumed water influxes. As we discussed in section 1, the order of magnitude of the rate coefficient is generally consistent with other models that include a substantial influx of water [e.g., Moore et

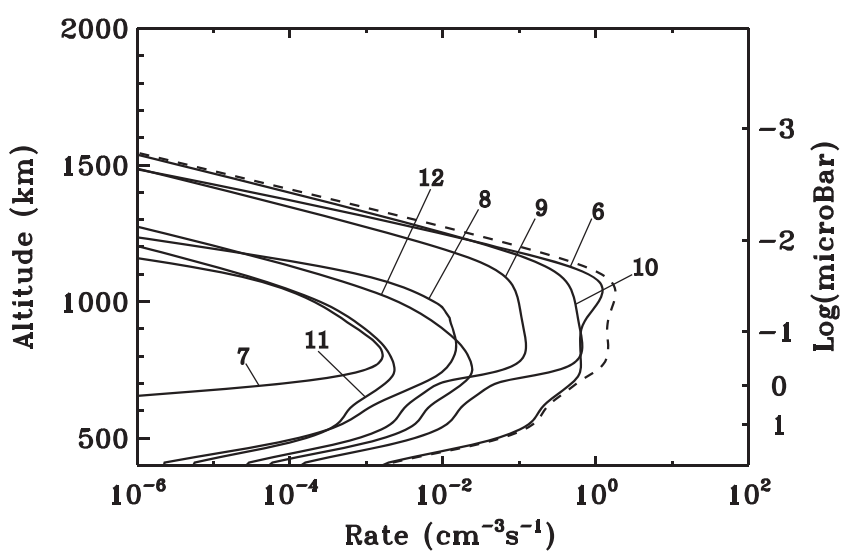

Figure 9. Primary production rate profiles of hydrocarbon ions due to reactions of the major non-hydrocarbon ions with hydrocarbons. The curves are labeled by the associated reactions (see text). The total production rate is shown with a dashed curve. The solar zenith angle of the model is $27^{\circ}$. 

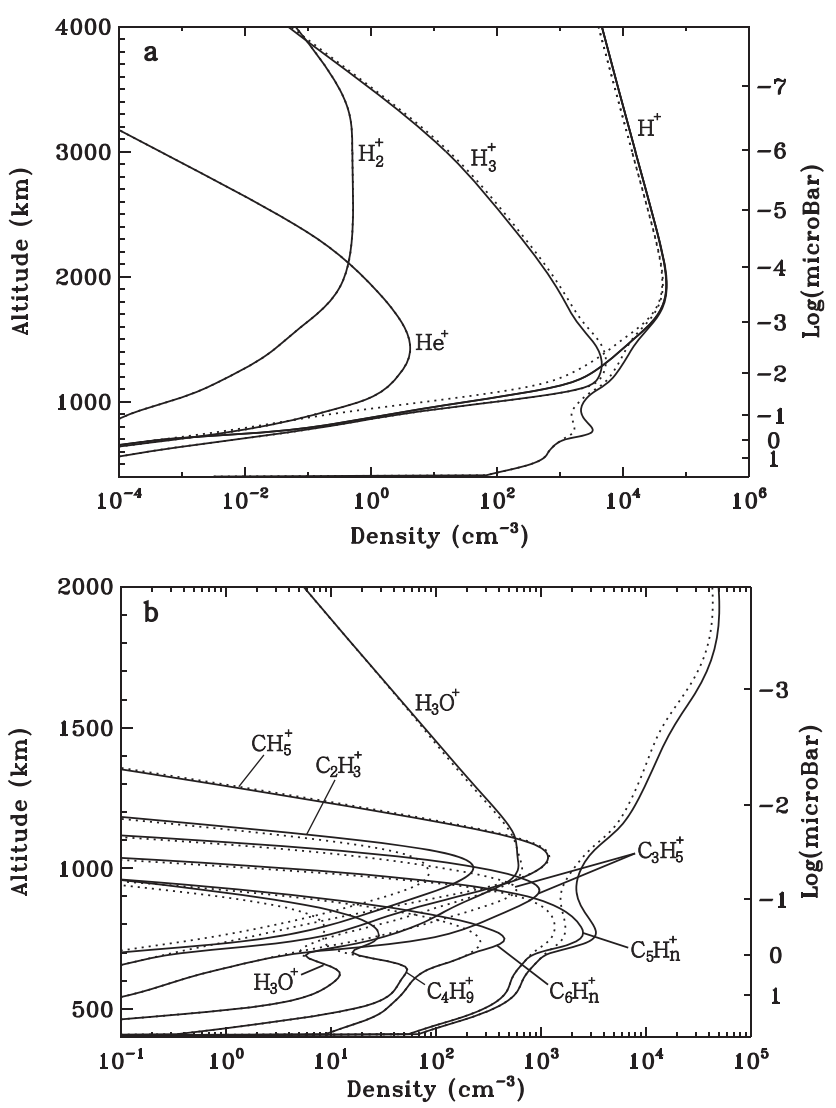

Figure 10. (a) Steady state density profiles of (nonhydrocarbon) $\mathrm{H}$ - and He-bearing ions. The total electron density for the high resolution model is shown with a thick curve in both parts of this figure. The solid and dotted curves are the densities for the high resolution and low resolution models, respectively. (b) Steady state density profiles of the major hydrocarbon and oxygen-bearing ions. Note the different altitude and density scales on the two parts of the figure. The solar zenith angle is $27^{\circ}$ and the magnetic dip angle is $45^{\circ}$.

$a l ., 2006,2010]$. For this assumption, however, loss of $\mathrm{H}^{+}$is dominated by reactions (9) and (10) below an altitude of $\sim 1100 \mathrm{~km} . \mathrm{H}^{+}$may also react with oxygen-bearing species, such as $\mathrm{H}_{2} \mathrm{O}$, to form $\mathrm{H}_{2} \mathrm{O}^{+}$(reaction (4)), and $\mathrm{H}_{3}^{+}$may react with $\mathrm{H}_{2} \mathrm{O}$ to form $\mathrm{H}_{3} \mathrm{O}^{+}$:

$$
\mathrm{H}_{3}^{+}+\mathrm{H}_{2} \mathrm{O} \rightarrow \mathrm{H}_{3} \mathrm{O}^{+}+\mathrm{H}_{2} .
$$

For such reactions, we have adopted as fixed the $\mathrm{H}_{2} \mathrm{O}$ density profile from the background model, which is shown in Figure 5.

[38] In Figure 10b, we present predicted altitude profiles of the densities of the major hydrocarbon ions and the sum of all the hydrocarbon ion densities on an expanded scale. The major hydrocarbon ions are found to be $\mathrm{CH}_{5}^{+}, \mathrm{C}_{2} \mathrm{H}_{3}^{+}, \mathrm{C}_{3} \mathrm{H}_{5}^{+}$, and $\mathrm{C}_{4} \mathrm{H}_{9}^{+}$, and the generic ions $\mathrm{C}_{5} \mathrm{H}_{n}^{+}$and $\mathrm{C}_{6} \mathrm{H}_{n}^{+}$. Although $\mathrm{CH}_{4}^{+}$is the dominant product of photoionization in the high resolution model, as shown in Figure 7b, the terminal ions are much heavier hydrocarbon ions that result from reactions between hydrocarbon ions and hydrocarbon neutrals. For the high resolution model, the sum of the hydrocarbon ion densities forms a peak with a maximum of about $3.2 \times$
$10^{3} \mathrm{~cm}^{-3}$ near $770 \mathrm{~km}(0.3 \mu \mathrm{bar})$; the peak for the low resolution model is $\sim 1.8 \times 10^{3} \mathrm{~cm}^{-3}$. The effect of the high resolution calculation is apparent in this model, but its relative magnitude depends upon the X-ray fluxes in the adopted solar spectrum. For this very low solar activity model, the $\mathrm{X}$-ray fluxes are relatively small. At higher solar activities, ionization by X-rays will be greater and may dominate the ionization on the bottomside.

[39] We can compare our model to the noon model of Moore et al. [2008], who adopted a high solar activity solar flux model, the EUV solar flux model for aeronomic calculations $\left(\right.$ EUVAC) for $F_{10.7}=267$. Despite the difference in solar activity, they predicted low-altitude electron densities that are similar to ours. Our calculations do not show, however, the dominance of $\mathrm{H}_{3}^{+}$that they predict up to nearly $2000 \mathrm{~km}$. Moore et al. [2009] adopted a wide variety of solar fluxes, including the TIMED/SEE fluxes for solar maximum [Woods et al., 2005, 2008]; they presented results for a high solar activity model for $1200 \mathrm{~h}$ local time that showed a peak in the hydrocarbon ion region (from about 500 to $700 \mathrm{~km}$ ) of $\sim 2 \times 10^{3} \mathrm{~cm}^{-3}$, which is similar to the magnitude of our lower peak at low solar activity. They also find, however, that the major ion is $\mathrm{H}_{3}^{+}$over the altitude range of about 900 to $1400 \mathrm{~km}$. There are many apparent differences between the model of Moore et al. [2009] and ours. For example, the ion production rates, including that of $\mathrm{H}_{2}^{+}$appear to be much larger than ours, sometimes by almost an order of magnitude. The difference may be tentatively ascribed to the lower solar activity of our model, but a verification will have to await the construction of high solar activity model, which is planned for the future.

\section{Summary and Conclusions}

[40] Radio occultation measurements have shown the existence of electron density layers near and below the main peaks on Saturn [e.g., Lindal et al., 1985; Nagy et al., 2006; Kliore et al., 2009], but the chemical identities of the ions that make up the lower layers are not well known. We have carried out calculations of the hydrocarbon ion densities in which the background neutral densities, including $\mathrm{H}_{2} \mathrm{O}$, the neutral temperatures, and the eddy diffusion coefficients, are adopted from the model of Moses and Vervack Jr. [2006] for the Voyager 1 egress UV solar occultation, for which the latitude is $27^{\circ} \mathrm{S}$; the homopause is near $1010 \mathrm{~km}$ above the 1 bar level $(0.04 \mu$ bar $)$. We have computed the density profile of $\mathrm{H}$ self-consistently in this model. In the "high resolution model", we adopt $\mathrm{H}_{2}$ absorption cross sections and solar fluxes that are characterized by a resolution of $0.001 \AA$ in the wavelength region from 842 to $1116 \AA$. In the "low resolution model", the high resolution fluxes are averaged over $1 \AA$ bins in this wavelength range.

[41] We have here shown that as for Jupiter, hydrocarbon ions are produced in abundance at low altitudes by direct ionization of hydrocarbon neutrals by photons that penetrate to below the methane homopause in the wings and gaps of the narrow $\mathrm{H}_{2}$ absorption lines between 842 and $1116 \AA$. The resulting photoionization rates for $\mathrm{H}$ and hydrocarbons in the high resolution model are significantly larger at low altitudes than are those for the low resolution model. Thus, we have shown that the photoionization rate profiles of atomic hydrogen and many hydrocarbons cannot be computed accurately with low resolution $\mathrm{H}_{2}$ absorption cross sections. 
[42] We have also found that the photoionization rates of hydrocarbons in the high resolution model compete in the same altitude range with reactions of hydrocarbon neutrals with non-hydrocarbon ions. The non-hydrocarbon ions are produced by the photoionization of $\mathrm{H}$ and by ionization of the major species $\mathrm{H}_{2}$ and $\mathrm{He}$ by soft and harder $\mathrm{X}$-rays and the concomitant energetic photoelectrons, secondary, and further ionizing electrons. Clearly, the solar spectrum at X-ray wavelengths, which is highly variable and not well characterized, is important in determining the X-ray and electron-impact ionization rate profile for $\mathrm{H}_{2}, \mathrm{He}$, and hydrocarbons.

[43] Finally, our photochemical model shows that a broad hydrocarbon ion region is produced in the altitude range of $650-1000 \mathrm{~km}$ above the 1 bar level $(2-0.044 \mu$ bar $)$, with a total peak density of $\sim 3.2 \times 10^{3} \mathrm{~cm}^{-3}$. This model is appropriate to low solar activity, and the hydrocarbon ion densities are expected to be significantly larger at higher solar activities by factors that cannot be predicted without a detailed calculation, which we plan for the future. As noted above, however, Moore et al. [2008, 2009] have constructed high solar activity models appropriate to noon conditions and have shown a lower peak in the ion and electron densities of $3 \times 10^{3} \mathrm{~cm}^{-3}$, which is comparable to our predictions for a much lower solar activity model.

[44] Since estimates of methane homopause pressure on Saturn are also variable [Nagy et al., 2009; Moses and Vervack Jr., 2006; Shemansky and Liu, 2012], the peak hydrocarbon ion densities and altitudes are almost certainly model dependent. In the future, we will carry out investigations that take into account thermospheric density profiles over the range derived from solar and stellar occultations from other spacecraft, including those of the recent Cassini spacecraft [e.g, Shemansky and Liu, 2012]. We note that we model here the photochemistry but not the layering due to gravity waves or wind shears that may affect the morphology of the electron density profiles [e.g., Lyons et al., 1992; Moses and Bass, 2000; Matcheva et al., 2001; Matcheva and Barrow, 2012].

[45] The model that we present here is a dayside steady state noon model, and therefore, it is not strictly comparable to those from RO profiles of Saturn, which are constrained to near-terminator SZAs and local times. The assumption of steady state at noon is a satisfactory approximation for the intermediate and terminal hydrocarbon ions, which are characterized by lifetimes that are less than $12-14 \mathrm{~min}$ near the peak altitudes of $740-810 \mathrm{~km}$. The approximation breaks down for longer-lived ions, such as protons. In order to model the density profiles near the terminators, and as a function of local time, we will in the future employ a time-dependent model that is similar to that which we used previously for Jupiter [Kim and Fox, 1991, 1994].

[46] The detection of Saturn electrostatic discharges has been interpreted as indicating that the peak electron densities on the dayside are large, exceeding $10^{5} \mathrm{~cm}^{-3}$, with large error bars and with a 1 to 2 orders of magnitude decrease from noon to midnight [e.g., Kaiser et al., 1984; Fischer et al., 2011; Moore et al., 2012]. For our high resolution model, the predicted $\mathrm{H}^{+}$peak densities near $1900 \mathrm{~km}$ are of the order of $5 \times 10^{4} \mathrm{~cm}^{-3}$. For the $\mathrm{H}_{2} \mathrm{O}$ profile that we adopt here, we find that the effective value of $k_{1}$ can be as small as $10^{-20} \mathrm{~cm}^{3} \mathrm{~s}^{-1}$ or as large as $10^{-16} \mathrm{~cm}^{3} \mathrm{~s}^{-1}$. The effective value of $k_{1}$ is strongly dependent on the local vibrational distribution of $\mathrm{H}_{2}(v)$, which is almost certainly not characterized by LTE.

[47] It is possible that the hydrocarbon ions that we have modeled here will continue to react with ambient neutrals, producing significant densities of higher hydrocarbon ions, the mass distribution of which is dominated by groups of terminal ions that are separated by $\sim 12 \mathrm{amu}$. This effect has been observed by the Cassini ion neutral mass spectrometer in the Titan ionosphere [e.g., Cravens et al., 2006; Vuitton et al., 2007]. The model that we present here, however, shows clearly that significant densities of hydrocarbon ions should be found below the methane homopause on Saturn, even at low solar activity.

[48] Acknowledgments. This work has been supported in part by grant NNX10AQ18G from the National Aeronautics and Space Administration to Wright State University. This work was supported in part by grants from the Swedish National Space Board. The Solar2000 research grade irradiances are provided courtesy of W. Kent Tobiska and SpaceWx.com. These historical irradiances have been developed with funding from the NASA UARS, TIMED, and SOHO missions.

[49] Masaki Fujimoto thanks the reviewers for their assistance in evaluating this paper.

\section{References}

Abgrall, H., E. Roueff, and I. Drira (2000), Total transition probability and spontaneous radiative dissociation of $\mathrm{B}, \mathrm{C}, \mathrm{B}^{\prime}$ and $\mathrm{D}$ states of molecular hydrogen, Astron. Astrophys. Suppl. Ser., 141, 297-300.

Anicich, V. G. (2003), An Index of the Literature for Bimolecular Gas Phase Cation-Molecule Reaction Kinetics, JPL Publication 03-19, California Institute of Technology, Pasadena, Calif.

Anicich, V. G., P. F. Wilson, and M. J. McEwan (2005), An ICR study of ion-molecule reactions relevant to Titan's atmosphere: An investigation of binary hydrocarbon mixtures up to 1 Micron, J. Am. Soc. Mass Spectrom., 16, 544-561, doi:10.1016/j.jasms.2005.11.022.

Atreya, S. (1986), Atmospheres and Ionospheres of the Outer Planets and Their Satellites, 111 p., Springer-Verlag, Berlin, Heidelberg.

Atreya, S. K., and T. M. Donahue (1975), The role of hydrocarbons in the ionospheres of the outer planets, Icarus, 25, 335-338.

Banaszkiewicz, M., L. M. Lara, R. Rodrigo, J. J. López-Moreno, and G. J. Molina-Cuberos (2000), A Coupled model of Titan's atmosphere and ionosphere, Icarus, 147, 386-404.

Backx, C., G. R. Wight, and M. J. Van der Wiel (1976), Oscillator strengths $(10-70 \mathrm{eV})$ for absorption, ionization, and dissociation of $\mathrm{H}_{2}, \mathrm{HD}, \mathrm{D}_{2}$, obtained by an electron-ion coincidence method, J. Phys. B.: Atom. Mole. Phys., 9, 315-331.

Banks, P. M., and G. Kockarts (1973), Aeronomy, Academic Press, New York.

Connerney, J. E. P., and J. H. Waite (1984), New model of Saturn's ionosphere with an influx of water from the rings, Nature, 312, 136-184.

Cravens, T. E. (1987), Vibrationally excited molecular hydrogen in the upper atmosphere of Jupiter, J. Geophys. Res., 92, 11,083-11,100.

Cravens, T. E., et al. (2006), Composition of Titan's ionosphere, Geophys. Res. Lett., 33, L07105, doi:10.1029/2005GL025575.

Cui, J., M. Galand, R. V. Yelle, V. Vuitton, J.-E. Wahlund, P. P. Lavvas, I. C. F. Müller-Wodarg, T. E. Cravens, W. T. Kasprzak, and J. H. Waite (2009), Diurnal variations of Titan's ionosphere, J. Geophys. Res., 114, A06310, doi:10.1029/2009JA014228.

Curdt, W., P. Brekke, U. Feldman, D. Wilhelm, B. N. Dwivedi, U. Schühle, and P. Lemaire (2001), The SUMER spectral atlas of solar-disk features, Astron. Astrophys., 375, 591-613.

Dalgarno, A., and G. Lejeune (1971), The absorption of electrons in atomic oxygen, Planet. Space Sci., 19, 1653-1657.

Dalgarno, A., and T. L. Stevens (1970), Discrete absorption and photodissociation of molecular hydrogen, Astrophys J., 160, L107-L109.

Fischer, G., D. A. Gurnett, P. Zarka, L. Moore, and U. A. Dyudina (2011), Peak electron densities in Saturn's ionosphere derived from the lowfrequency cutoff of Saturn lightning, J. Geophys. Res., 116, A04315, doi:10.1029/2010JA0161887.

Florescu-Mitchell, A. I., and J. B. A. Mitchell (2006), Dissociative recombination, Physics Reports, 430, 277-374.

Fox, J. L., and J. H. Black (1989), Photodissociation of CO in the thermosphere of Venus, Geophys. Res. Lett., 16, 291-294. 
Fox, J. L., and A. J. Weber (2012), MGS electron density profiles: Analysis and modeling of peak altitudes, Icarus, 221, 1002-1019, doi:10.1016/j.icarus.2012.10.002.

Galand, M., L. Moore, B. Charnay, I. Müller-Wodarg, and M. Mendillo (2009), Solar primary and secondary ionization at Saturn, J. Geophys. Res., 114, A06313, doi:10.1029/2008JA013981.

Hallett, J. T., D. E. Shemansky, and X. Liu (2005), A rotational-level hydrogen physical chemistry model for general astrophysical applications, Astrophys. J., 624, 448-461.

Hanson, W. B., S. Sanatani, and D. R. Zuccaro (1977), The Martian ionosphere as observed by the Viking retarding potential analyzers, $J$. Geophys. Res., 82, 4351-4367.

Hartogh, P., et al. (2011), Direct detection of the Enceladus water torus with Herschel, Astron. Astrophys., 532, L2.

Hinson, D. P., and R. A. Simpson (2008), Mars Global Surveyor Radio Occultation Profiles of the Ionosphere-Reorganized. vol. USA_NASA_JPL_MORS_1102, data set MGS-M-RSS-5-EDS-V1.0, NASA Planetary Data System.

Hinteregger, H. E., K. Fukui, and B. R. Gibson (1981), Observational, reference and model data on solar EUV, from measurements on AE-E, Geophys. Res. Lett., 8, 1147-1150.

Huestis, D. L. (2005), $\mathrm{H}^{+}+\mathrm{H}_{2}$ ion-molecule reactions in the ionospheres of the outer planets, Bull. Am. Astron. Soc., 37, 757.

Huestis, D. L., S. W. Bougher, J. L. Fox, M. Galand, R. E. Johnson, J. I. Moses, and J. C. Pickering (2008), Cross sections and reaction rates for comparative planetary aeronomy, Space Sci. Rev., 139, 63-105.

Ichihara, A., O. Iwamoto, and R. K. Janev (2000), Cross sections for the reaction of $\mathrm{H}^{+}+\mathrm{H}_{2}(v=0,14) \rightarrow \mathrm{H}+\mathrm{H}_{2}^{+}$at low collision energies, $J$. Phys. B., 33, 4747-4758.

Johnsen, R., and S. L. Guberman (2010), Dissociative recombination of $\mathrm{H}_{3}^{+}$ ions with electrons: Theory and experiment, Adv. At. Mol. Opt. Phy., 59, $75-128$.

Kaiser, M. L., M. D. Desch, and J. E. P. Connerney (1984), Saturn's ionosphere: Inferred electron densities, J. Geophys. Res., 89, 2371-2376.

Keller, C. N., V. G. Anicich, and T. E. Cravens (1998), Model of Titan's ionosphere with complete hydrocarbon chemistry, Planet. Space Sci., 46, 1157-1174.

Kim, Y. H., and J. L. Fox (1991), The Jovian ionospheric E region, Geophys. Res. Lett., 18, 123-126.

Kim, Y. H., and J. L. Fox (1994), The chemistry of hydrocarbon ions in the Jovian ionosphere, Icarus, 112, 310-325.

Kliore, A. J., I. R. Patel, G. F. Lindal, D. N. Sweetnam, H. B. Hotz, J. H. Waite, and T. R. McDonough (1980), Structure of the ionosphere and atmosphere of Saturn from Pioneer 11 Saturn radio occultation, $J$. Geophys. Res., 85, 5857-5870.

Kliore, A. J., A. F. Nagy, E. A. Marouf, A. Anabtawi, E. Barbinis, D. U. Fleishman, and D. S. Kahah (2009), Midlatitude and highlatitude electron density profiles in the ionosphere of Saturn obtained by Cassini radio occultation measurements, J. Geophys. Res., 114, A04315, doi:10.1029/2008JA013900.

Krstić, P. (2002), Inelastic processes from vibrationally excited states in slow $\mathrm{H}^{+}+\mathrm{H}_{2}$ and $\mathrm{H}+\mathrm{H}_{2}^{+}$collisions: Excitations and charge transfer, Phys. Rev. A, 66, 042717.

Lavvas, P., M. Galand, R. V. Yelle, A. N. Heays, B. R. Lewis, G. R. Lewis, and A. J. Coates (2011), Energy deposition and primary chemical products in Titan's upper atmosphere, Icarus, 213, 233-251.

Lindal, G. F., D. N. Sweetnam, and V. R. Eshleman (1985), The atmosphere of Saturn: An analysis of the Voyager radio occultation measurements, Astron. J., 90, 1136-1146.

Lyons, J. R., Y. L. Yung, and M. Allen (1992), Solar control of the upper atmosphere of Triton, Science, 246, 1483.

Majeed, T., and J. C. McConnell (1991), The upper ionospheres of Jupiter and Saturn, Planet. Space Sci., 39, 1715-1732.

Majeed, T., and J. C. McConnell (1996), Voyager electron density measurements on Saturn: Analysis with a time-dependent ionospheric model, $J$. Geophys. Res., 101, 7589-7598.

Majeed, T., J. C. McConnell, and R. V. Yelle (1991), Vibrationally excited $\mathrm{H}_{2}$ in the outer planets thermosphere-Fluorescence in the Lyman and Werner bands, Planet. Space Sci., 39, 1591-1606.

Majeed, T., J. H. Waite, S. W. Bougher, R. V. Yelle, G. R. Gladstone, J. C. McConnell, and A. Bhardwaj (2004), The ionospheres-thermospheres of the giant planets, Adv. Space Res., 33, 197-211.

Matcheva, K. I., and D. J. Barrow (2012), Small scale variability in Saturn's lower ionosphere, Icarus, 221, 525-543.

Matcheva, K. I., D. F. Strobel, and F. M. Flasar (2001), Interaction of gravity waves with ionospheric plasma: Implications for Jupiter's ionosphere, Icarus, 152, 347-365.

McElroy, M. B. (1973), The ionospheres of the major planets, Space Sci. Rev., 14, 460-473.
Melin, H., S. Miller, T. Stallard, L. M. Trafton, and T. R. Geballe (2007) Variability in the $\mathrm{H}_{3}^{+}$emission of Saturn: Consequences for ionisation rates and temperature, Icarus, 186, 234-241.

Moore, L., and M. Mendillo (2007), Are plasma depletions in Saturn's ionosphere a signature of time-dependent water input Geophys. Res. Lett., 34, L12202, doi:10.1029/2007GL029381.

Moore, L., M. Mendillo, I. Müller-Wodarg, and D. L. Murr (2004), Modeling of global variations and ring shadowing in Saturn's ionosphere, Icarus, 172, 503-520.

Moore, L., A. F. Nagy, A. J. Kliore, I. Müller-Wodarg, J. D. Richardson, and M. Mendillo (2006), Cassini radio occultations of Saturn's ionosphere: Model comparisons using a constant water flux, Geophys. Res. Lett., 33, L22202, doi:10.1029/2006GL027375.

Moore, L., M. Galand, I. Müller-Wodarg, R. Yelle, and M. Mendillo (2008), Plasma temperatures in Saturn's ionosphere, J. Geophys. Res., 113, A10306, doi:10.1029/2008JA013373.

Moore, L., M. Galand, I. Müller-Wodarg, and M. Mendillo (2009), Response of Saturn's ionosphere to solar radiation: Testing parameterizations for thermal electron heating and secondary ionization processes, Planet. Space Sci., 57, 1699-1705.

Moore, L, I. Müller-Wodarg, M. Galand, A. Kliore, and M. Mendillo (2010), Latitudinal variations in Saturn's ionosphere: Cassini measurements and model comparisons, J. Geophys. Res., 115, A11317, doi:10.1029/2010JA105692.

Moore, L., G. Fischer, I. Müller-Wodarg, M. Galand, and M. Mendillo (2012), Diurnal variation of electron density in Saturn's ionosphere: Model comparisons with Saturn electrostatic discharge (SED) observations, Icarus, 221, 508-516.

Moses, J. I., and S. F. Bass (2000), The effects of external material on the chemistry and structure of Saturn's ionosphere, J. Geophys. Res., 105, 7013-7052.

Moses, J. I., and R. J. Vervack Jr. (2006), The structure of the upper atmosphere of Saturn, 37th Annual Lunar and Planetary Science Conference, March 13-17, League City, Tex., Abstract \# 1803.

Müller-Wodarg, I. C. F., L. Moore, M. Galand, S. Miller, and M. Mendillo (2012), Magnetosphere-atmosphere coupling at Saturn: 1-Response of thermosphere and ionosphere to steady state polar forcing, Icarus, 221, 481-494.

Nagy, A. F., et al. (2006), First results from the ionospheric radio occultations of Saturn by the Cassini spacecraft, J. Geophys. Res., 111, A06310, doi:10.1029/2005JA011519.

Nagy, A. F., A. J. Kliore, M. Mendillo, S. Miller, L. Moore, J. I. Moses, I. Müller-Wodarg, and D. Shemansky (2009), Upper atmosphere and ionosphere of Saturn, in Saturn After Cassini-Huygens, edited by M. K. Dougherty et al., pp. 181-201, Springer Science+Business Media B. V., Berlin, doi:10.1007/978-1-4020-09217-6 8.

Pagani, L., C. Vastel, E. Hugo, V. Kokoouline, C. H. Green, A. Bacmann, E. Bayet, C. Ceccarelli, R. Peng, and S. Schlemmer (2009), Chemical modeling of L183 (L134N): An estimate of the ortho/para $\mathrm{H}_{2}$ ratio, Astron. Astrophys., 494, 623-626.

Perry, J. J., Y. H. Kim, J. L. Fox, and H. S. Porter (1999), Chemistry of the Jovian auroral ionosphere, J. Geophys. Res., 104, 16,541-16,565.

Shemansky, D. E., and X. Liu (2012), Saturn upper atmospheric structure from Cassini EUV and FUV occultations, Can. J. Phys., 90, 817-831, doi:10.1139/p2012-036.

Stallard, T., S. Miller, G. Ballester, D. Rego, R. D. Joseph, and L. M. Trafton (1999), The $\mathrm{H}_{3}^{+}$latitudinal profile of Saturn, Astrophys. J., 521, L149-L152.

Tobiska, W. K. (2004), SOLAR2000 irradiances for climate change, aeronomy and space system engineering, Adv. Space. Res., 34(8), 1736-1746.

Vuitton, V., R. V. Yelle, and M. J. McEwan (2007), Ion chemistry and N-containing molecules in Titan's upper atmosphere, Icarus, 191, $722-742$

Vuitton, V., R. V. Yelle, and P. Lavvas (2009), Composition and chemistry of Titan's thermosphere and ionosphere, Phil. Trans. Roy. Soc., 367, 729-741

Waite, J. H. (1981), The ionosphere of Saturn, PhD thesis, Univ. of Michigan, Ann Arbor, Mich.

Waite, J. H., S. K. Atreya, and A. F. Nagy (1979), The ionosphere of Saturn: Predictions for Pioneer 11, Geophys. Res. Lett., 6, 723-726.

Waite, J. H., et al. (2006), Cassini ion and neutral mass spectrometer: Enceladus plume composition and structure, Science, 311, 1419-1422

Witasse, O., T. Cravens, M. Mendillo, J. Moses, A. Kliore, A. F. Nagy, and T. Breus (2008), Solar system ionospheres, Space Sci. Rev., 139, 235-266.

Woodall, J., M. Agundez, A. J. Markwick-Kemper, and T. J. Millar (2007), The UMIST database for astrochemistry 2006, Astron. Astrophys., 466 , 1197-1204. 


\section{KIM ET AL.: HYDROCARBON IONS ON SATURN}

Woods, T. N., F. G. Eparvier, S. M. Bailey, P. C. Chamberlin, J. Lean, G. J. Rottman, S. C. Solomon, W. K. Tobiska, and D. L. Woodraska (2005), The solar EUV experiment (SEE): Mission overview and first results, J. Geophys. Res., 110, A01312, doi:10.1029/ 2004JA010765.

Woods, T. N., P. C. Chamberlin, W. K. Peterson, R. R. Meier, P. G. Richards, D. J. Strickland, G. Lu, L. Qian, S. C. Solomon, B. A. Iijima, A. J. Mannucci, and B. T. Tsurutani (2008), XUV photometer system: Improved solar irradiance algorithm using CHIANTI spectral models, Sol. Phys., 250, 235-267.
Wilson, E. H., and S. K. Atreya (2004), Current state of modeling the photochemistry of Titan's mutually dependent atmosphere and ionosphere, J. Geophys. Res., 109, E06002, doi:10.1029/2003JE002181.

Yan, M., H. R. Sadeghpour, and A. Dalgarno (1998), Photoionization cross sections of $\mathrm{He}$ and $\mathrm{H}_{2}$, Astrophys. J., 496, 1044-1050, Erratum in Astrophys. J., 559, 1194-1194, 2001.

Yelle, R. V., and S. Miller (2004), Jupiter's thermosphere and ionosphere, in Jupiter: The Planets, Satellites, and Magnetosphere, edited by F. Bagenal, T. Dowling, and W. McKinnon, pp. 185-218, Cambridge Univ. Press, Cambridge, U. K. 